\title{
A SYMBOL OF INFINITE (BE)LONGING: PSYCHOSOCIAL RHYTHMS OF INCLUSION AND EXCLUSION AT SOUTH AFRICAN UNIVERSITIES
}

\author{
S. Liccardo \\ Department of Psychology \\ Faculty of Humanities \\ University of Pretoria, \\ Pretoria, South Africa \\ e-mail: sabrina.liccardo@gmail.com
}

\section{ABSTRACT}

This article argues that the life histories of Black South African women scientists provide a telling story of psychosocial trans-formations because they experience the world as outliers; paradoxically positioned within an interstitial space of (non)being between their dual sense of inclusion in and exclusion from marginal and dominant groups. Using a narrative method to enquire into the lives of fourteen scholarship students in Science, Technology, Engineering, and Mathematics (STEM) fields at a historically white South African university (HWU), this article proposes an infinity model to illustrate how these young women locate their-selves in the field of higher education through recognition, dislocate their-selves from the field through misrecognition and infinitely recreate new subjectivities and epistemic communities at the intersecting space in between inclusion-exclusion.

Keywords: black women in science, inclusion and exclusion, belonging, knowledge-that and knowledge-how, cultural capital, community cultural wealth

\section{INTRODUCTION}

The racialised gender gap in STEM fields raises critical concerns around the politics of scientific enquiry and the continued marginalisation of Black women in higher education and society. Several South African universities have responded to the challenge of recruiting and retaining Black women in STEM fields by providing academic support scholarship programmes that include them into historically white institutional structures, such as the STEM scholarship programme on which this investigation is based. While these programmes do make a contribution to changing the demographic composition of the STEM workforce, what is also needed is a radical change of institutional cultures and practices inherited from the colonial and apartheid past and exacerbated by neoliberal economic forces.

The current fallist student movement for free education and decolonisation of the university in Africa is a critical moment of confrontation with what W. E. B. du Bois (2013, 
119) has called "the problem of the color-line”. It is a stark reminder that whiteness comprises the Gold Standard of the "colour-line" as evident in the widening gap between the rhetoric of transformation and the lived experiences of Black students and academics at South African universities. Scientific endeavour needs to be demythologized as a white male achievement. How could the positionality of young Black women in STEM fields unmask the normative constructions of science and scientists as white and masculine? To address this question, the article is based on a wider qualitative study, which is framed by a narrative complex system of human being, becoming and belonging (see Figure 1). I have adapted this model from Maldonado-Torres' (2016, 20 and 30) “analytics of coloniality” and “analytics of decoloniality” which I will discuss in relation to Levine’s (2015) analysis of four abstract forms ("Whole, Rhythm, Hierarchy, Network”) with the aim of (dis)entangling the Lacanian registers of the imaginary, symbolic and real.

As depicted in Figure 1, the “coloniality” (Quijano, 2000) and decoloniality of real space, imaginary power and symbolic knowledge include three subsystems: 1) the discursivecirculatory system of human being, situated at the bottom of the hierarchy, 2) the storiednervous system of human becoming, situated at the top of the hierarchy and 3) the narrativerespiratory system of human belonging is situated in-between. The narrative complex system will be discussed further in a book project, but this article will focus on the discursivecirculatory system of human being. The "colour-line” (Du Bois 2013) horizontally splits this hierarchy into the "zone of being” and the "zone of non-being” (Fanon 1967). As Grosfoguel (2016, 11) notes:

"Racialization occurs through the marking of bodies. Some bodies are racialized as superior and other bodies are racialized as inferior ... those subjects located above the line of the human, as superior, live in what Afro-Caribbean philosophers following Fanon's work called the 'zone of being,' while subjects that live on the inferior side of the demarcating line live in the 'zone of nonbeing' (Fanon 1967; Gordon 2006; Wynter 2003; Maldonado-Torres 2008).”

Gordon $(2015,59)$ further explains, "Whereas there is a conception of normality for whites that is, their being 'human' by virtue of being white - there is no such thing for blacks”. Whiteness is equated with "being" or normality in relation to the construction of "non-being". The "colour-line" or colour racism in our society structurally positions black people in the "zone of non-being" at the bottom of the hierarchy in relation to the position of white people as being "human" at the top of the hierarchy. The intersection of racism and sexism is a lived reality for women of colour, as Crenshaw $(1989,149)$ notes: "[Similar to a traffic in an intersection], if a Black woman is harmed because she is in the intersection, her injury could result from sex discrimination or race discrimination”. This binary hierarchical id-entity is also vertically split by the logics of neoliberalism, globalisation and financialisation in which differently positioned 


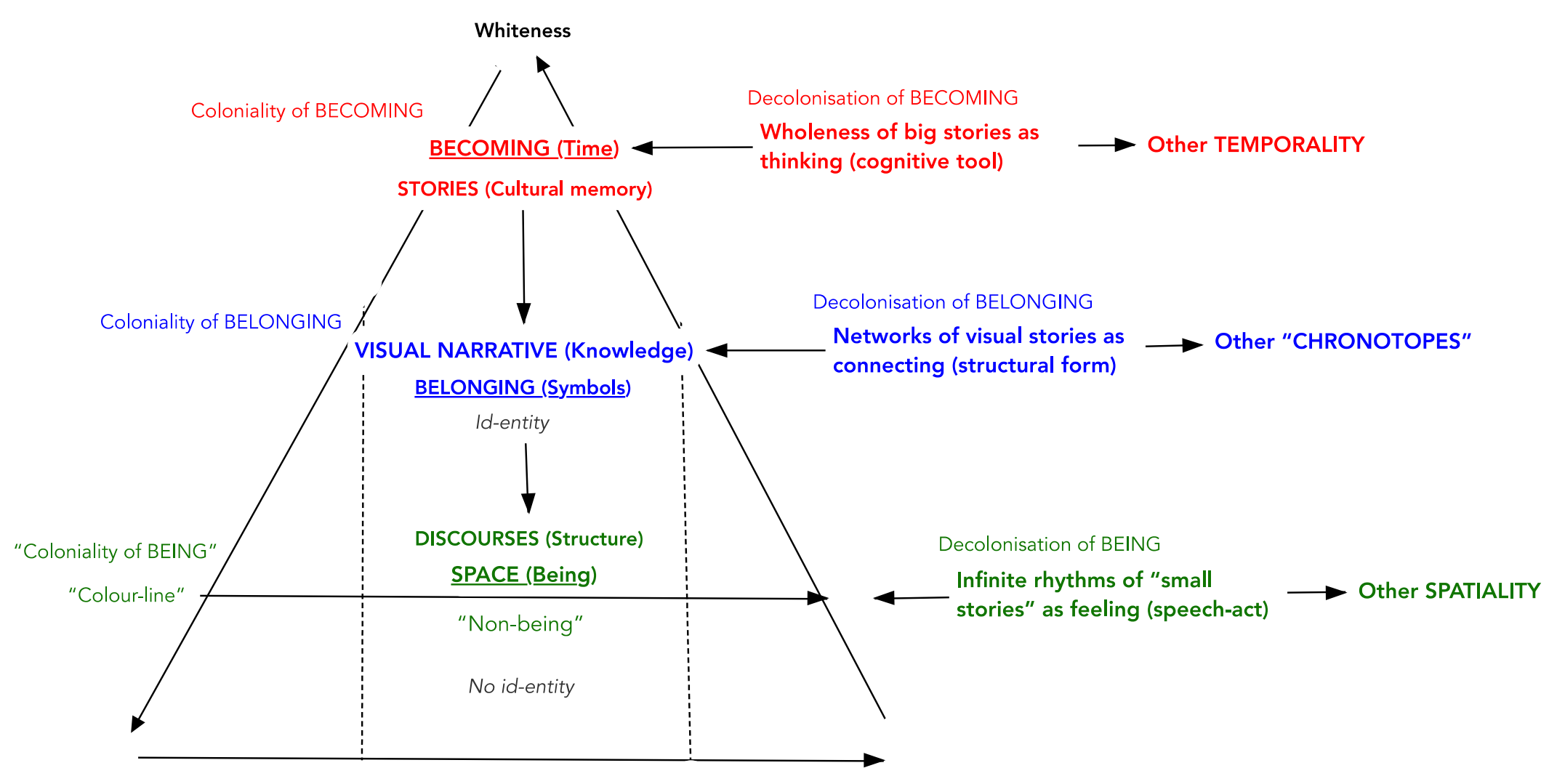

Figure 1: Eurocentric and Afrocentric forms of human (non)being, (not)becoming and (no)belonging (redrawn from Maldonado-Torres, 2016) 
agents and institutions compete in a constant struggle to reach the mirage of "being" which is centred at the top of the hierarchy, as depicted in Figure 1. Black women scientists are outliers in South African universities (Liccardo and Bradbury 2017) as they are marginally positioned in the "zone of non-being" (by the intersection of race and gender) and centrally positioned in the "zone of being" (by their STEM degrees which are highly valued in the “capitalist/imperial/patriarchal/racial/colonial world-system” (Grosfoguel 2016, 13)). Their simultaneous (and limited) access to these paradoxical zones of "non-being" and "being" creates shifting senses of self-identification and inclusion as well as dis-identification and exclusion from academic communities which make explicit the normative constructions of science and scientists as white and masculine.

Accordingly, in this article I examine the micro-politics of identity positioning among young Black women in STEM fields at a HWU to address three research questions: 1) How do these women locate or position themselves as scientists in the making and with what consequences? 2) How do institutional practices welcome new entrants to the STEM-HWU field and/or serve to safeguard the economic interests and values of the dominant normative group? 3) How do these women resist the inclusion-exclusion logic and recreate subjectivities that connect them to other spaces of (be)longing?

\section{METHODOLOGY}

Stories provide an interpretive entry point to understanding the interrelationship between psychic and social realities (Andrews, Squire and Tamboukou 2008, 4). Using a "biographicnarrative interview method” (Wengraf 2011) to inquire into the lives of fourteen graduate students, the focus is on their positionalities and alternating senses of inclusion and exclusion to academic communities as they navigate institutional spaces that continue to be dominated by white men and privileged forms of knowledge production processes. Each interview was approximately one hour in duration, audio-recorded, and transcribed. The focus is on their “small stories” (Bamberg and Georgakopoulou 2008) as performances of identity positioning within the social structure of the everyday.

The women in this study were recipients of a STEM scholarship programme at a HWU. The goal of this programme was to provide first-generation, academically talented Black ${ }^{1}$ South African women whose families have scarce financial resources with the necessary academic, social and financial support to graduate with STEM degrees. My relation to these women influenced the kinds of stories they chose to tell in the interviews and the kinds of stories I choose to tell in this research. For instance, as an internal evaluator of their scholarship programme, I was complicit in constructing the programme's criteria of “academic talent" that was informed by the university's standards of excellence. During the interviews, these women 
told me stories about academic failure as a way of critically re-evaluating this discourse of “academic talent”. Thus, a significant portion of this article is dedicated to explaining how practices of exclusion at the study site have shaped their experiences of inclusion and academic failure. Furthermore, as a white, middle-class, South African woman, I cannot identify with their experiences of living in the "matrix of domination" (Collins 2000). Rather, the aim of this research is to make sense of their paradoxical positionality within an interstitial space of (non)being through their life narratives or theorisations about the artificial and material quality of social structure.

\section{ANALYSIS AND DISCUSSION: AN INFINITY SYMBOL AS A THEORETICAL- EMPIRICAL FRAMEWORK}

I propose an infinity symbol as a theoretical-empirical framework to illustrate the psychosocial rhythms of inclusion-exclusion and the reproductions of disciplinary and institutional cultures at HWUs. The intersecting space in-between represents an infinite state of being in longing for a sense of home (see Figure 2).

I use an infinity symbol as a metaphor to examine how rhythms of small group stories could puncture the "coloniality of being” (Maldonado-Torres 2007) and activate other spatialities. To construct this framework I have drawn on multiple theoretical strands, as will be discussed later. Hall (1996, 5-6) argues that the link between psychic and social reality could be theorised as "identity":

"I use 'identity' to refer to the meeting point, the point of suture ... points of temporary attachment to the subject positions which discursive practices construct for us (see Hall, 1995). They are the result of a successful articulation or 'chaining' of the subject into the flow of the discourse, what Stephen Heath, in his path-breaking essay on 'Suture' called 'an intersection' $(1981,106) . ”$

The infinity symbol represents the relational self as a psychosocial phenomenon narrated in the dialectical interplay between our dual positions as subjects that shape the world but in turn are shaped by the world in which we act (Mishler 1999, 18). Similar to the dynamism of the infinity symbol, the relational self is a verb because it always re-locates itself in relation to the similarities and differences provided by an-other (Fay 1996, 37). This never-ending relation between self and other or self-identification and self-differentiation creates infinite rhythms of (dis)location and (be)longing. It is at this space within infinity, an ever-changing present, where we renegotiate, reconfigure, reimagine, and rewrite ourselves as-another but within conditional limitations, as will be discussed later. The intersecting space in between inclusion-exclusion, located at the middle of the symbol, represents an infinite state of resistance in which these 
INCLUSION (psychic reality)

"Academic habitus": Locat ing ident ity positions in the field

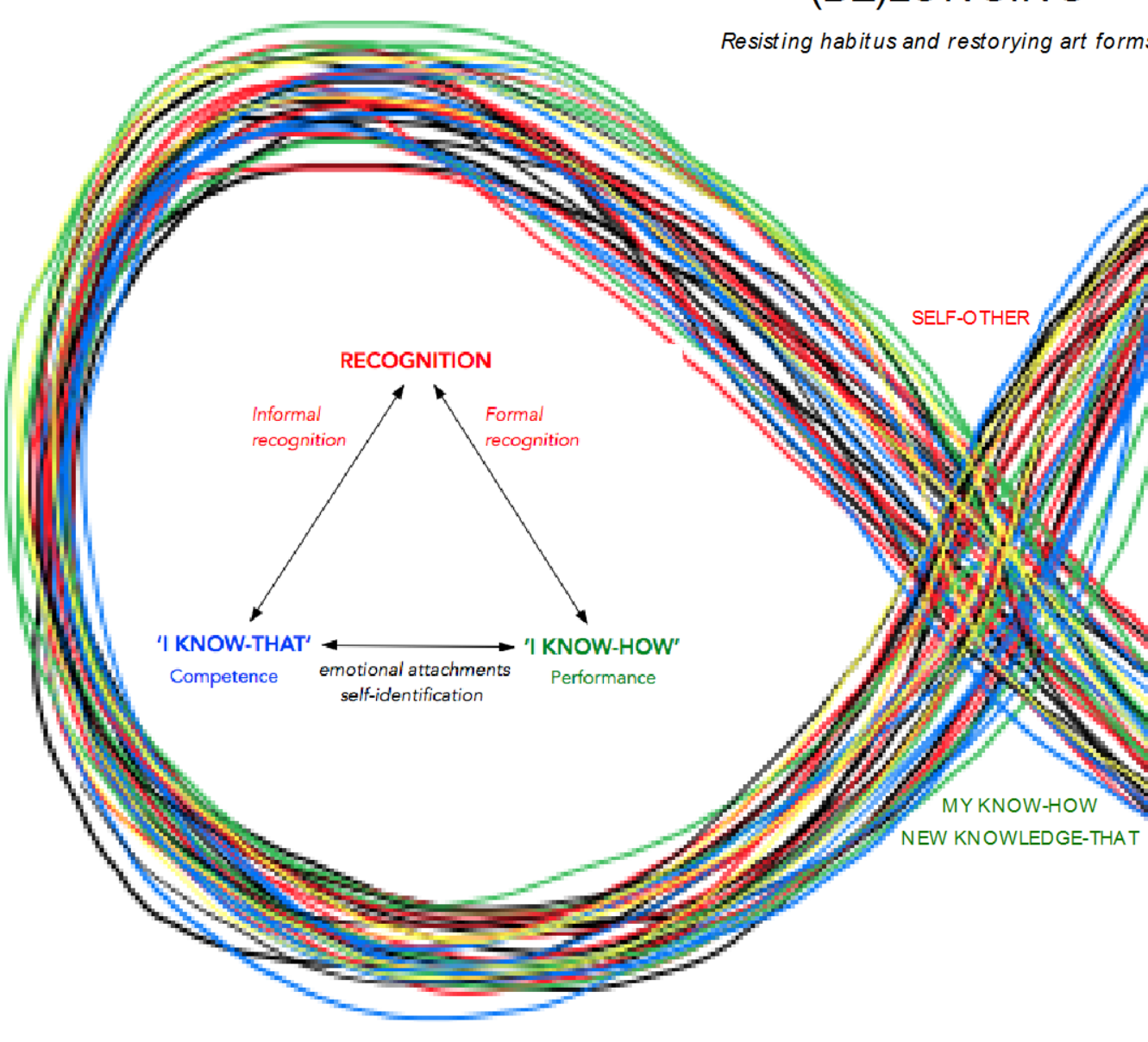

\section{EXCLUSION (social structure)}

"Habitus clivé" : Dislocating ident ity positions in the field

Figure 2: A symbol of infinite (be)longing 
women (re)member their disconnected selves into meaningful "wholes" in the form of life stories. The (re)creation of life stories at this space within infinity facilitates the development of "differential consciousness" (Sandoval 1991), new kinds of subjectivities and other spatialities and temporalities. In the words of Sandoval $(1991,139)$ :

"Differential consciousness ... is accessed through poetic modes of expression: gestures, music, images, sounds, words that plummet or rise through signification to find some void - some noplace - to claim their due ... it is a conduit brought about by any system of signification capable of evoking and puncturing through to another site, to that of differential consciousness.”

Over time, these patterns of "psychosocial transformation" (Duncan, Stevens and Canham 2014) are weaved into a tapestry of meanings that bind the material/symbolic, social/personal, and historical/psychical. This network of interconnections coalesces in individual life narratives, which emphasise the inherent entanglement between the individual, social, cultural and historical (Kuhn 2002, 5). The infinity symbol, as self-relations lived in the social structure of the everyday, is thus illustrative of (de)coloniality as a rhythmic process of degeneration and regeneration cross-linking generations. This article explores how these rhythmic patterns are grounded in practices of recognition and misrecognition that generate the inclusion-exclusion logic, thus, creating a sense of alienation for young Black women in STEM fields and a longing for a place to call home.

Bourdieu's $(1984,101)$ equation “[(habitus)(capital)] + field = practice” in combination with the following concepts will be used as a basis for constructing a conceptual framework that accounts for students' narratives of inclusion-exclusion and (be)longing at South African universities: "the politics of belonging" (Yuval-Davis 2006); "model of science identity" (Carlone and Johnson 2007); "knowledge-how" and "knowledge-that" (Ryle 1945) and “epistemological access” (Morrow 2007); “academic habitus” (Bourdieu and Wacquant 1992); “intersectionality" (Crenshaw 1991) and the "matrix of domination” (Collins 2000); "habitus clivé” (Bourdieu 2004) and; “community cultural wealth” (Yosso 2005).

\section{RECOGNITION, INCLUSION AND “ACADEMIC HABITUS”: LOCATING IDENTITY POSITIONS IN THE FIELD OF HIGHER EDUCATION}

I will now address the first research question: how do these women locate or position themselves as scientists in the making and with what consequences? As represented by the left infinity loop in Figure 2, these women are included in the field through practices of formal and informal recognition, which leads to an "academic habitus” (Bourdieu and Wacquant 1992). This "academic habitus" is developed through their self-identifications with the statements "I know-that" (competence) and "I know-how" (performance or practical reasoning). Inclusion is 
thus constructed through self-identifications, social bonds and emotional attachments to feeling located in an academic community. In this section I will draw on the women's narratives to explore their feelings of inclusion, the production of inclusion and the effects of being included into the field of higher education in general and the STEM-HWU field in particular.

These women feel included in an academic community of practice when they self-identify with being an intellectual and a scientist. For example, Takalani's identification with being an intellectual is evident in her statement, “I’m knowledgeable, I am a genius”.

Takalani: "When I passed my matric, I was [awarded for being] one of the top students in my province. I think I was like number twenty-one in the whole province. So I defined myself as being someone who knows. I'm knowledgeable. I am a genius.”

The formal recognition that Takalani received for her academic performance (know-how) defined who she believed herself to be. To explain how these women position themselves as intellectuals and scientists in the making, I will draw on Carlone and Johnson's (2007) model of science identity in relation to Ryle's (1945) concepts of "knowledge-how" and "knowledge-that". Carlone and Johnson $(2007,1190)$ theorise a prototype of the kind of person with a strong science identity:

"She is competent; she demonstrates meaningful knowledge and understanding of science content and is motivated to understand the world scientifically. She also has the requisite skills to perform for others her competence with scientific practices ... Further, she recognizes herself, and gets recognized by others, as a science person.” (Own emphasis).

This model is based on three interrelated elements of science identity, namely competence, performance, and recognition. Similarly, Ryle $(1945,4)$ differentiates between "knowledgethat" (factual knowledge) and "knowledge-how" (practical reasoning). Thus, knowing-that refers to one's competence in the acquisition of factual knowledge whereas knowing-how demonstrates one's skill in the performance or application of knowledge to particular situations (refer to the left loop in Figure 2). Nosakhele, for instance, developed a passion for biology through her teacher's informal recognition of her intellectual ability and encouragement to develop her competence (or knowledge-that) in this subject:

Nosakhele: "They [teachers] pushed me and encouraged me to perhaps consider studying what makes me happy, right, and then I remember talking to my biology teacher in Grade 10. He said to me, 'now it's time that you identify [textbook] chapters which you really like', right. And then I fell in love with genetics. And then that's when I actually started now going to the library, reading more about genetics, just the basic stuff on genetics.”

In this excerpt, Nosakhele identifies with being a science person through her teachers' informal 
recognition of her intellectual ability which leads to an emotional investment in this identity position in the form of "going to the library, reading more about genetics" and thus developing her competence in the "basic stuff” or knowledge-that. Similar to Takalani, Itumeleng mentions that academic work is not simply “what I do” (knowing-that) but rather "who I am” (knowinghow):

Itumeleng: "That [receiving an academic award] is where I felt I was smart. It showed me or it made me into who I am.”

Itumeleng also identifies with being an intellectual when her performance in science (knowhow) is formally recognised by members within a community of practice. The recognition of shared characteristics with other members in the community establishes the foundation for solidarity and creates a sense of inclusion. Through the conferment of academic awards, Itumeleng is able to position herself and is positioned by others as a scientist in the making.

During their primary, secondary and tertiary education, this group of women developed an "academic habitus" (Bourdieu and Wacquant 1992) by internalising the standards of meritocratic excellence in the form of being recognised as "academically talented". These women thus believed that their success at university would be dependent on their individual talent and hard work, and that their background knowledge and social locations would not interfere in their pursuit for a STEM degree. As noted by Alala:

Alala: "First year was really difficult. First year was awful because you come from a place [primary and secondary school] where you worked hard or you listened in class and you produced the work and you got the results. So it was simple. And now you come in [to university] and you work hard, you don't sleep, you put in all your work and, you put your heart into the work, and it comes back with these results and then you are like, 'but why?'.”

As a result, their experiences of academic failure at university created intense feelings of shame, depression, and inferiority because being an academically talented student became part of who they understood themselves to be rather than something that they did.

\section{MISRECOGNITION, EXCLUSION AND "HABITUS CLIVÉ": DISLOCATING IDENTITY POSITIONS IN THE FIELD OF HIGHER EDUCATION}

In this section, I will address the second research question: how do institutional practices welcome new entrants to the STEM-HWU field and/or serve to safeguard the economic interests and values of the dominant group? As represented by the right infinity loop in Figure 2 , these women are excluded from the field through practices of misrecognition, which leads to "habitus clivé” (Bourdieu 2004). The creation of "habitus clivé” is evident in the statements "I 
don’t know-that” (“incompetence”) and “I don’t know-how” (inferiority complex). Academic failure becomes the breaking point at which they dis-identify from their positioning of being and becoming scientists. Exclusion is thus constructed through dis-identifications and emotional detachments or feeling dislocated from an academic community. I will draw on the women's narratives to explore their feelings of exclusion, the reproduction of exclusion and the effects of simultaneously being included and excluded in the STEM-HWU field.

These women feel excluded from an academic community of practice when they disidentify with being an intellectual or a scientist. For example, Welile's sense of exclusion is evident in her statement, "I am just a failure”.

Welile: "It was the whole [academic] exclusion part. I never ever thought I would ever get excluded, ever, ever, not even in my life did I think that is something that would happen to me. So when I was excluded and then I made a decision - an arrogant decision - you know, to leave [the university] and just go do something else. I think that I also felt that I disappointed my sponsors you know, never mind my family, I just felt that I disappointed the people that had invested in me. So I am failing ... I just remember that I just cried all the time. I told [the project manager] that I didn't want to come back, that they must give the scholarship to somebody else who is more deserving because I am just a failure ... I am not going to do that [apply for readmission] because I didn't want to bring myself down to that level, you know."

Inclusion is constructed through shared characteristics with other "academically talented" individuals who have risen to the top of a hierarchy of honour in a merit-based culture. For the reward of recognition to be reinforcing, it is essential that not everyone be recognised as academically talented. These women position themselves as academically talented in relation to the difference provided by others who do not do well academically. However, Welile's experience of failure and academic exclusion had "brought [her]self down to that level” where she feels excluded from the top achievers who are recognised as members of an academic community.

I will now discuss the reproduction of exclusion in relation to background knowledge, habitus and "epistemological access” (Morrow 2007). Bourdieu (1986, 243) argues that class is experienced at the level of the body because our patterns of consumption are embodied as dispositions ("habitus") and materialise in degrees of symbolic power ("forms of capital”). Habitus and capital determine which strategies an agent is likely to adopt in manoeuvring symbolic power in a field, which is structured by implicit rules that serve the economic interests of the dominant actors. Cultural and social capital are "disguised forms of economic capital [which is] at the root of their effects" (Bourdieu 1986, 251). Practice, as the interplay between one's habitus and forms of capital, positions an agent within the field (Bourdieu 1986, 250).

The diverse educational and socio-economic backgrounds that students come from 
manifest in different kinds of capital or background knowledge (of knowledge-that and knowledge-how) in preparation for university. Students who are situated in privileged class positions (those who come from private schools and former Model C schools) have developed the kind of "academic habitus" (particularly knowledge-how), which facilitates their “epistemological access” (Morrow 2007) to HWUs (see, for example, Liccardo, Botsis and Dominguez-Whitehead 2015, 379). The normalisation and legitimisation of white middle class habitus, which serves the interests of the dominant group in the field of higher education, are represented as equal opportunity for all. However, agents do not compete on a level playing field as their socially made (valued) bodily dispositions are raced, gendered and classed. Naidoo (2004) has noted that, in South Africa, academic excellence is associated with the "intrinsic" dispositions of individuals from the white schooling system.

In the excerpt that follows, Alala believed that her lecturers failed to make explicit their rules of knowing-how to apply knowledge-that to a particular assignment.

Alala: 'Do you know what they kept saying Sabrina, 'you're just, you are just not there yet' ... And I would ask them [the lecturers] I remember one thing in my last crit, it was a roof project for construction, and I had, I had over designed it or over thought it, that's what he said. I mean there was a simple solution but I couldn't find one so I worked on it. I worked on the detail and I tried to figure out different ways to make sure that the water doesn't go into the building, it worked, it was expensive I understand, but it worked Sabrina and he said to me 'I had over designed it and that's why I would fail'. I mean if I'm over designing then doesn't that mean that I'm thinking about this and that I'm trying, and I actually got a solution. Even though it wasn't an ideal one - it wasn't ideal, it would have been expensive - but then I had tried you know. I don't think overthinking is a problem, I don't think you fail a person for overthinking.”

In this case, Alala is treated as a passive recipient of knowledge-that instead of an active agent who is trying to learn-how to solve problems and construct knowledge. The "Mister Mastery Mystery Phenomenon” (Ahrentzen and Anthony 1993, 16) demonstrates that instead of teaching Alala in knowledge-how, her lecturers kept their practices a mystery by saying, "you are just not there yet”. As a result, Alala is led to believe that this "mystery” implies the mastery of the lecturer, who is typically a white mister in STEM fields. These "white misters" (and white women) or "men as masters of the discipline" may occupy their positions of power in the university field without much critical reflection on their practice and thus fail to inculcate their students into the discipline of knowledge.

I will now explain how exclusion is reproduced through the politics of belonging to a STEM-HWU field. As agents possess varying forms and degrees of social and cultural capital, power struggles emerge between the agents who attempt to preserve or disrupt the regulative principles within specific fields (Bourdieu 1998, 44). I understand a field to be synonymous with the politics of a "community of practice” (Lave and Wenger 1991). If the influential 
members in a scientific community of practice are predominately white, male and middle class, then the dispositions that are normalised in the field will be white, masculine and middle class (see, for example, Booi, Vincent and Liccardo 2017, 507). Through the process of socialisation these members have internalised the implicit regulative principles that govern middle-class fields. These members are more likely to perform action sequences (habits) that would reproduce the interests, values and cultures of the dominant classes.

It is clear that agency is shaped by the structuring principles and opportunities provided by the field. While some agents are in a position to use the field's possibilities to realise their own economic interests, others are forced to adapt to the structures of the field by sublimating themselves. This is what Yuval-Davis $(2011,10)$ refers to as the politics of belonging, which entails a "specific political project aimed at constructing belonging to particular collectivity/ies which are themselves being constructed in these projects in very specific ways and in very specific boundaries". Historically white universities play a central role in "the binding and marking of symbolic boundaries” (Hall 1996, 17) by constructing a criteria of inclusion to a particular collectivity that embody white, masculine, middle-class dispositions with the aim of reproducing the values, interests and practices of the dominant group. This results in contestations around community membership and its associated status and entitlements which raise a critical question, "What is required from a specific person for him/her to be entitled to belong, to be considered as belonging, to the collectivity?” (Yuval-Davis 2006, 209). The rewriting of one's self thus takes place within conditional limitations because membership rights of belonging are about meeting these criteria of inclusion, which are stratified along the line of normality.

This research demonstrates that institutionalised practices of (mis)recognition operate to perpetuate the marginalised position of Black working-class women. In other words, the power struggles to disrupt the regulative principles of a field which reproduce social inequality are masked as a competition for meritocratic recognition. The intersections of race, class and gender locations in field coalesce into the "matrix of domination” (Collins 2000), positioning young Black women as pawns in the institutional field of play. For instance, the interlocking race and gender locations that Takalani occupies in the STEM-HWU field obstructs her lecturer and peers from trusting her academic ability.

Takalani: “Being the only Black lady [in my third and fourth year class] I think - I don't know if I saw this wrong - but I think lecturers lack to trust me. They didn't trust me and also because the lecturers couldn't trust me the kids in class also couldn't [trust me] because the thing is while he's busy lecturing there, he would keep his eyes on me and he'll always ask if I understand - he'll never ask the whole class if they understand - he'll just bring it to me like, 'do you understand?'. And then after the class, he'll be like [call my surname and say] 'please stay behind', then I would stay behind and he would 
be like 'did you really get that?' and I was like, 'yes I got it', 'you can come to my office if you need more lessons and stuff' and it was like 'why me?' I got what you're saying even if I didn't get it, I'll just go back and study. I think that also started creating - the other kids started to see that I was the only Black lady in class - so when we had to do groups ... I would be there, left with no one ... I'd just go to the lecturer and then he'll ask some people to just like put me in [their group] and some would even say 'no' like just say 'no we can’t work with her' ... so I was like 'what!?'.”

In this incident, Takalani explains how lecturers, in positions of power and influence, reject Black women's bid to be recognised as meeting the inclusion criteria as legitimate students in STEM fields. Takalani, who does not reflect the dominant white, masculine and middle-class habitus, is positioned as incompetent (as not knowing-that and not knowing-how) by others, which delegitimizes her membership in a community of learning. As a result, Takalani fights against her lecturer's racist and sexist stereotypes because she is placed in a position in which she needs to convince her peers that she will not be an incompetent team member.

The STEM-HWU space could be viewed as a psychosocial battlefield in which these women's collective (scarred) memories materialize into "habitus clivé” (Bourdieu 2004). In the excerpt below, Alala uses the following slogan to depict her life-long battle to be heard, "life is war, keep fighting”:

Alala: “It's a war, it's a battle ... 'life is war', you have to keep fighting, sometimes you don't want to wake up in the morning but you have to. You have to keep fighting. In Biko's book he also always said, it's your mind, that it's your mind, they talk about the colonised mind ... we have to fight for ideas to be heard ... we're not there yet, we have a long way ahead I mean even, it's like, we have to fight for our ideas to be heard. We still have to fight for a stake. We still have to fight with ourselves.”

The racialised, gendered and class habitus of the STEM-HWU field generates practices of “symbolic violence” (Bourdieu and Wacquant 1992; Bulhan 2004; Fanon 1967) in that it provides young Black women access to its field but simultaneously blocks their participation and progression within the field by its rules of the meritocratic (mis)recognition game thus creating ancillary feelings of inferiority for young Black women in STEM disciplines. The effects of exclusion and academic failure make these women feel like "I don't know-that" (or incompetent) and “I don’t know-how” (or inferior, "like you're not worth being there”). For instance, Takalani's sense of her self as academically talented is "beaten up” or damaged by failure, which "has become a part of her".

Takalani: "Like some of them [students who fail], they feel so beaten up, they just want to give up and just do something else because they feel they have wasted too much energy, so many years, so much life. I think that pain [of failure] it has become so much that you have to live with it, it becomes too sinked in - even if it's over - I don't think it ends when you graduate, it doesn't, I mean the pain is over but it becomes a part of you.” 
The painful memories caused by incidences of failure materialise as "scars” (noted by Alala in the next section) that resurface the feeling of not knowing-that and not knowing-how in present situations. It is evident that these women have struggled to reconcile the disjunction between their "academic habitus" with the STEM-HWU field, which led to "habitus clivé". In other words, their "habitus clivé", or cleft habitus illustrate the emotional labour required to navigate and reconcile their simultaneous feelings of inclusion in and exclusion from marginal and dominant groups.

\section{(BE)LONGING: RESISTING HABITUS AND RESTORYING ART FORMS}

I will now address the final research question: how do these women resist the inclusionexclusion logic and recreate subjectivities that connect them to other spaces of (be)longing? The middle space within infinity represents an intersecting site of feedback loops where the women resist habitus and story new art forms through "my knowledge-how" which has the potential of recreating "new knowledge-that” (see Figure 2). (Be)longing or longing to belong is constructed through “community cultural wealth” (Yosso 2005) which opens up other spaces for constructing new epistemic communities and cultures. From a Critical Race Theory perspective, Yosso $(2005,77)$ provides a critique of Bourdieu's theory of cultural capital by proposing "community cultural wealth" which includes the following forms of capital: “aspirational, linguistic, familial, social, navigational, and resistant capital”. I will now provide an example of "resistant capital" and "navigational capital"; however, this section will be discussed at length in a book project. Alala confronts racial oppression with her poem, which could be read as "resistant capital":

\footnotetext{
"I must wear the face of a hungry lion

Stared as equals to roaring

Pacing, for I am hungry

Pacing, for I am hunting

Pacing, for I am tired

We have no faces

Just scars and our delicate insides

Wolves wear our faces

The time is now

Let us find our way back to our race

Who is man? Human.”
}

In her poem, Alala alludes to how black people are treated as if they "have no faces". As a result, they need to "wear the face of a hungry lion" to affirm their humanity in defiance of interlocking racialised, gendered and class oppressions that mark their everyday spaces. The critical race and feminist studies that Odirile was exposed to in postgraduate studies equipped 
her with the critical thinking skills and "navigational capital” to strategically reposition herself within the institution.

Odirile: "It was during this time [postgraduate studies] when I started to read a lot and understand what it is be a Black woman in Africa, what it means to be a Black architect in South Africa and in the world ... to be a woman and the roles that you wear. For me the biggest issue was how the course was structured. Why should I learn about these things [critical race and feminist studies] only in Honours? Why don't I have to learn critical thinking in undergrad. [I would've had] more time to read and engage in the subject matter ... and understand the way I grew up, I want to explore these things [incidents of marginalisation] because of disadvantage and white privilege, where you come from does influence where you go to."

Odirile's critical race and feminist studies enabled her to perceive personal experiences of marginality as a condition of social structure, rather than personal inadequacies. Education, as learning to think critically about the world, was the vehicle through which she was able to recognise the possibility of creating new ways of doing science and being an architect in South Africa, thus, shifting the normative constructions of science and scientist. Odirile's undergraduate curriculum design "reflects a systemic failure by the educational system to initiate these students into the world of academic study and its implicit rules of enquiry and knowledge construction” (Bradbury and Miller 2011, 8). This systematic failure to inculcate students in disciplines of knowledge through the lens of critical thinking restricts the possibilities for "pedagogic interruption” (Bernstein 1996) and subversion of dominant institutional cultures.

\section{CONCLUSION}

This article has proposed an infinity model to illustrate the psychosocial rhythms of inclusion and exclusion at South African universities. The findings indicate that young Black women scientists are included in the field of higher education through practices of (in)formal recognition, leading to "academic habitus" in which they self-identify with the statements "I know-that” (competence) and "I know-how" (performance or practical reasoning). Conversely, these women are excluded from the field through practices of misrecognition, leading to "habitus clivé” and the statements “I don’t know-that” (“incompetence”) and "I don’t knowhow" (inferiority complex). The intersecting space in between inclusion-exclusion represents a site where these women resist habitus and enstory new art forms, within conditional limitations, through "my knowledge-how" which has the potential of recreating "new knowledge-that". (Be)longing is forged with "community cultural wealth" (Yosso 2005) which opens up other spaces for recreating new epistemic communities and cultures of knowledge production. 


\section{ACKNOWLEDGMENTS}

Portions of this article were presented at a conference on Decolonising the University in Africa, 17-18 August 2016, University of South Africa (UNISA). I would like to thank the Higher Education Institutional Cultures, Equity and Transformation (HEICET) research project and Rhodes University for the travel funds.

\section{NOTE}

1. "Black" is utilised as an overarching term for African, Coloured (mixed-race) and Indian. The apartheid-era racial categories are used as redress measures of transformation.

\section{REFERENCES}

Ahrentzen, S. and K. H. Anthony. 1993. Sex, stars, and studios: A look at gendered educational practices in architecture. Journal of Architectural Education 47(1): 11-29.

Andrews, M., C. Squire and M. Tamboukou. 2008. Doing narrative research. London: Sage.

Bamberg, M. and A. Georgakopoulou. 2008. Small stories as a new perspective in narrative and identity analysis. Journal of Language, Discourse Communication Studies 28(3): 377-396.

Bernstein, B. 1996. Pedagogy, symbolic control and identity: Theory, research, critique. London: Taylor and Francis.

Booi, M., L. Vincent and S. Liccardo. 2017. Counting on demographic equity to transform institutional cultures at historically white South African universities? Higher Education Research \& Development 36(3): 498-510.

Bourdieu, P. 1986. The forms of capital. In Handbook of theory and research for the sociology of education, ed. J. G. Richardson, 241-258. New York: Greenwood Press.

Bourdieu, P. 1984. Distinction: A social critique of the judgement of taste Trans. R. Nice. Cambridge, MA: Harvard University Press.

Bourdieu, P. 1998. The state nobility: Elite schools in the field of power. Oxford: Oxford University Press.

Bourdieu, P. 2004. Esquisse pour une Auto-Analyse. Paris: Editions Raisons D’Agir.

Bourdieu, P. and L. Wacquant. 1992. An invitation to reflexive sociology. Chicago: University of Chicago Press.

Bradbury, J. and R. Miller. 2011. A failure by any other name: The phenomenon of underpreparedness. South African Journal of Science 107(3-4): 1-8.

Bulhan, H. A. 2004. Frantz Fanon and the psychology of oppression. Massachusetts: Boston University Boston.

Carlone, H. B. and A. Johnson. 2007. Understanding the science experiences of successful women of color: Science identity as an analytic lens. Journal of Research in Science Teaching 44(8): 11871218.

Collins, P. H. 2000. Black feminist thought: Knowledge, consciousness, and the politics of empowerment. London: HarperCollins

Crenshaw, K. 1991. Mapping the margins: Intersectionality, identity politics, and violence against women of color. Stanford Law Review 43(6): 1241-1299.

Crenshaw, K. 1989. Demarginalizing the intersection of race and sex: A black feminist critique of antidiscrimination doctrine, feminist theory and antiracist politics. University of Chicago Legal Forum: 139-168. 
Du Bois, W. E. B. 2013. The problem of the color line at the turn of the twentieth century: The essential early essays, edited by N. D. Chandler. New York, NY: Fordham University Press.

Duncan, N., G. Stevens and H. Canham. 2014. Living through the legacy: The Apartheid Archive Project and the possibilities for psychosocial transformation. South African Journal of Psychology 44(3): 282-291.

Fay, B. 1996. Contemporary philosophy of social science. Oxford: Blackwell.

Fanon, F. 1967. Black skin, white masks. New York: Grove Press.

Gordon, L. R. 2006. African-American philosophy, race, and the geography of reason. In Not only the master's tools: African-American studies in theory and practice, ed. L. R. Gordon and J. A. Gordon, 3-50. Boulder and London: Paradigm.

Gordon, L. R. 2015. What Fanon said: A philosophical introduction to his life and thought. New York: Fordham University Press.

Grosfoguel, R. 2016. What is racism? Journal of World-System Research 22(1): 9-15. http://jwsr.pitt.edu/ojs/index.php/jwsr/article/view/609/743 (Accessed 2 March 2017).

Hall, S. 1995. Fantasy, identity, polities. In Cultural Remix: Theories of Politics and the Popular, ed. E. Carter, J. Donald and J. Squites. London: Lawrence \& Wishar.

Hall, S. 1996. Who needs “identity”? In Questions of cultural identity, ed. S. Hall and P. Du Gay, 1-17. London: Sage.

Heath, S. 1981. Questions of Cinema. Basingstoke: Macmillan.

Kuhn, A. 2002. Family secrets: Acts of memory and imagination. London: Verso.

Lave, J. and E. Wenger. 1991. Situated learning: Legitimate peripheral participation. Cambridge: Cambridge University Press.

Levine, C. 2015. Forms: Whole, rhythm, hierarchy, network. Princeton \& Oxford: Princeton University Press.

Liccardo, S., H. Botsis and Y. Dominguez-Whitehead. 2015. Background knowledge and epistemological access: Challenges facing black women in a SET Scholarship Programme. South African Journal of Higher Education 29(1): 375-393.

Liccardo, S. and B. Bradbury. 2017. Black women scientists: Outliers in South African universities. African Journal of Mathematics, Science and Technology Education. http://dx.doi.org/ 10.1080/18117295.2017.1371980

Maldonado-Torres, N. 2007. On the coloniality of being: Contributions to the development of a concept. Cultural studies 21(2-3): 240-270.

Maldonado-Torres, N., 2008. Against War. Durham: Duke University Press.

Maldonado-Torres, N. 2016. Outline of ten theses on coloniality and decoloniality. http://frantzfanonfoundation-fondationfrantzfanon.com/IMG/pdf/maldonado-torres_outline_of_ ten_theses-10.23.16_.pdf (Accessed 14 January 2017).

Mishler, E. 1999. Storylines: Craftartists' narratives of identity. Cambridge, MA: Harvard University Press.

Morrow, W. E. 2007. Learning to teach in South Africa. Cape Town: HSRC Press.

Naidoo, R., 2004. Fields and institutional strategy: Bourdieu on the relationship between higher education, inequality and society. British Journal of Sociology of Education 25(4): 457-471.

Quijano, A. 2000. Coloniality of power and Eurocentrism in Latin America. International Sociology 15(2): 215-232.

Ryle, G. 1945. Knowing how and knowing that: The presidential address. Proceedings of the Aristotelian Society 46: 1-16.

Sandoval, Chela. 1991. Methodology of the oppressed. London: University of Minnesota Press.

Wengraf, T. 2011. Interviewing for life histories, lived situations and personal experience: The 
biographic-narrative interpretive method (BNIM). Short guide to BNIM interviewing and interpretation. London East Research Institute: University of East London, UK.

Wynter, S. 2003. Unsettling the coloniality of being/power/truth/freedom: Towards the human, after man, its overrepresentation - an argument. CR: The New Centennial Review 3(3): 257-337.

Yosso, T. J. 2005. Whose culture has capital? A critical race theory discussion of community cultural wealth. Race Ethnicity and Education 8(1): 69-91.

Yuval-Davis, N. 2006. Belonging and the politics of belonging. Patterns of Prejudice 40(3): 197-214.

Yuval-Davis, N. 2011. The politics of belonging: Intersectional contestations. London: Sage. 